\title{
Perancangan Tata Letak Stasiun Kerja dengan Menggunakan Metode Systematic Layout Planning
}

\author{
Elfania Hartari ${ }^{1 *}$, Dene Herwanto ${ }^{2}$ \\ 1,2 Teknik Industri Universitas Singaperbangsa Karawang \\ Jl. HS.Ronggo Waluyo, Puseurjaya, Kec. Telukjambe Timur, Kabupaten Karawang, Jawa Barat 41361 \\ 1*elfania.hartari17057@student.unsika.ac.id \\ ${ }^{2}$ dene.herwanto@ft.unsika.ac.id
}

\section{Work Station Layout Design Using The Systematic Layout Planning Method}

Dikirimkan : 06, 2021. Diterima : 09, 2021. Dipublikasikan : 09, 2021

\begin{abstract}
PT. Adhimix Precast Indonesia is engaged in the construction sector by producing concrete and construction. Layout design is needed so that the existing land can be utilized optimally and material transfer is more effective and efficient. This can affect the distance and time of the transfer so that the cost of moving can be minimized. In practice, the company's trajectory condition only has one path (trajectory) for alternating current and crossing production lines, so it is considered inefficient to move both goods and workers, coupled with the existence of land that is not used properly, therefore improvements are needed to the production floor layout. in order to minimize the cost of moving goods and have a definite path (trajectory). Systematic Layout Planning (SLP) is a method for redesigning a layout (re-layout) based on the results of distance optimization and Material Handling Costs (OMH). The amount of OMH in the initial layout (now) is Rp. 2,614,200 with a total track distance of $39.82 \mathrm{~m}$ and $\mathrm{OMH}$ in the proposed layout with a total track distance of $19.17 \mathrm{~m}$, the result is Rp. 1,534,200, this proves that the proposed layout can be applied because there is a decrease in total OMH by $35.44 \%$ or $R p .926,580$.
\end{abstract}

Keywords - Systematic Layout Planning (SLP); Material Handling Costs; Retreading; Layout

\begin{abstract}
Abstrak- PT. Adhimix Precast Indonesia bergerak di bidang pembangunan dengan memproduksi beton dan konstruksi. Perancangan tata letak diperlukan agar lahan yang ada dapat dimanfaatkan dengan maksimal dan pepindahan material lebih efektif dan efisien. Hal ini dapat mempengaruhi besar jarak dan waktu perpindahan sehingga besar biaya perpindahan dapat diminimalkan. Pada pelaksanaannya kondisi lintasan perusahaan hanya memiliki satu jalur (lintasan) untuk arus bolak balik dan persilangan alur produksi maka dianggap tidak efisien untuk dilakukan perpindahan baik barang maupun pekerja, ditambah dengan adanya lahan yang tidak dimanfaatkan dengan baik oleh karena itu dibutuhkan perbaikan pada layout lantai produksi agar dapat meminimalkan biaya perpindahan barang dan memiliki jalur (lintasan) yang pasti. Systematic Layout Planning (SLP) merupakan metode untuk membuat perancangan ulang suatu layout (re-layout) berdasarkan hasil dari optimalisasi jarak dan Ongkos Material Handling (OMH). Besar OMH pada layout awal (sekarang) adalah Rp 2.614.200 dengan total jarak lintasan 39,82m dan $\mathrm{OMH}$ pada layout usulan dengan total jarak lintasan $19,17 \mathrm{~m}$ didapat hasil sebesar Rp. 1.534.200, hal ini membuktikan bahwa layout usulan dapat diterapkan karena terjadi penurunan total OMH sebesar 35,44\% atau Rp. 926.580.
\end{abstract}

Kata kunci - Systematic Layout Planning (SLP); Ongkos Material Handling; Vulkanisir; Tata Letak

\section{PENDAHULUAN}

PT. Adhimix Precast Indonesia adalah perusahaan yang bergerak di bidang konstruksi sebagai penghasil beton cetak, cair, dan kerangka konstruksi. Terdapat Unit Manufaktur yang didalamnya memiliki 3 divisi yaitu Truck Mixer
(TM), Vulkanisir dan Konstruksi. Berdasarkan pemesanan ban yang tinggi setiap bulannya maka divisi Vulkanisir dalam operasionalnya diharapkan produktivitas yang tinggi dengan total biaya produksi yang minimum, sehingga produksi yang berjalan dapat lebih efektif dan efisien. 
Pada suatu produksi, tata letak dari stasiun kerja memiliki peran penting dalam kegiatan produksi. Untuk membuat suatu pencangan ulang tata letak stasiun kerja yang baru diperlukan observasi guna mengetahui hubungan antar stasiun kerja. Permasalahan yang biasa terjadi pada tata letak diantaranya lantai produksi yang tidak tersusun dengan baik akibat dari jarak antara satu mesin dengan mesin yang lainnya tidak berurutan sehingga banyak terjadi arus bolak balik yang secara langsung akan mengurangi tingkat efisiensi lantai produksi. [1].

Pada divisi Vulkanisir mesin yang penggunannya berurutan dalam rangkaian proses produksi diletakkan secara berjauhan. Hal ini mempengaruhi jarak lintasan dan mengakibatkan terjadinya arus bolak - balik dan persilangan alur produksi. Maka perlu dilakukan perancangan ulang pada tata letak stasiun kerja untuk dapat menghasilkan proses produksi optimal, menghemat pemakaian ruang produksi sehingga perpindahan material dan pekerja dari suatu stasiun ke stasiun lain lebih efektif dan efisien.

Ban vulkanisir merupakan ban dengan kondisi yang lebih tua yang bagian permukaan lintasan telah dilapis menggukan karet veneer tapak atau tread liner dengan menerapkan metode yang membantu untuk obligasi veneer ke ban yang lebih tua tersebut dengan sangat kuat sehingga akan sulit bahkan tidak mungkin untuk membedakan ban vulkanisir dengan ban baru. [2]

Penelitan mengenai tata letak stasiun kerja telah banyak dilakukan para peneliti diantaranya [3] yang membahas tentang re-layout pabrik vulkanisir, [4] perancangan tata letak menggunakan metode Automated Layout Design Program (ALDEP), [5] menjelaskan bagaimana perancangan tata letak dibuat berdasarkan metode konvensional, [6] minimasi ongkos material handling dengan membuat perancangan ulang tata letak menggunakan metode grafik dan CRAFT, dll.

System layout planning merupakan metode untuk melakukan perancangan ulang tata letak lantai produksi di Unit Manufaktur PT. Adhimix Precast Indonesia agar tempat yang ada dapat digunakan dengan maksimal. Menggunakan Flow To Chart (FTC) dan Activity Relaionship Chart (ARC) untuk merancang layout baru dari stasiun kerja yang kemudian dihitung besar ongkos material handling $(\mathrm{OMH})$ nya.

\section{METODOLOGI PENELITIAN}

\section{A. Langkah Penelitian}

Penelitian ini dilakukan untuk membuat suatu perancangan ulang pada layout stasiun kerja terkait dengan efesiensi jalur lintasan untuk pemindahan material antar stasiun kerja di bagian Vulkanisir pada Unit Manufaktur PT. Adhimix Precast Indoesia.

Pengumpulan data dilakukan dengan mengukur ukuran stasun kerja secara langsung mengunakan alat bantu roll meter dan pengukuran waktu perpindahan material menggunakan stopwatch.

Proses pengerjaan jurnal ini secara berurutan dan lebih jelas dapat dilihat pada Gambar 1 .

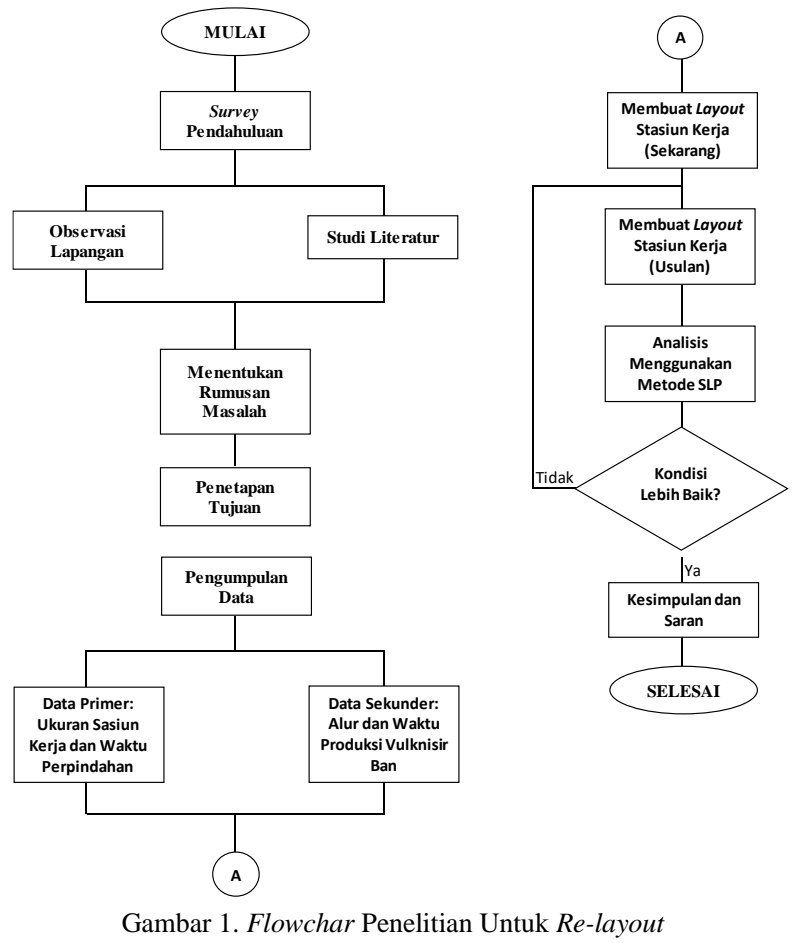

\section{B. Perancangan Sistem Kerja}

Perancangan sistem kerja adalah suatu usaha yang diupayakan untuk membuat suatu rancangan dan perbaikan dari sistem kerja dengan tetap memperhatikan elemen - elemen sistem kerja lainnya secara integral. Adanya perancangan sistem kerja dapat mendukung pelaksanaan proses kerja agar lebih efektif dan efisien sehingga dapat dicapai hasil kerja atau produksi yang lebih maksimal. Pelaksanaan perancangan sistem kerja dalam suatu perusahaan dapat berjalan dengan adanya asperk aspek pendukung berjalannya suatu produksi atau kerja yaitu manusia (man), mesin (machine), material (material) dan peralatan kerja.

Perancangan sistem kerja dapat dibagi menjadi 3 macam diantaranya:

Sistem kerja: Perancangan sistem kerja yang fokus menganalisis sistem yang akan dibuat atau yang sudah ada untuk bahan pertimbangan perbaikan sistem. Adapun sistem terdiri dari manusia (pekerja), mesin, bahan material, serta lingkungan kerja yang melakukan interaksi untuk membuat produk berkualitas dengan produktivitas tinggi. 
Produktivitas: Perancangan sistem kerja yang dilakukan berdasarkan hasil perhitungan dari perbandingan (efektivitas) dengan input (efisiensi).

$$
\mathrm{P}=\mathrm{O} / \mathrm{I} \text {. }
$$

dimana, $\mathrm{P}=$ produktivitas

$$
\begin{aligned}
\mathrm{O} & =\text { output } \\
\mathrm{I} & =\text { input }
\end{aligned}
$$

Analisis perancangan kerja: kegiatan yang bertujuan untuk memahami bagaimana prinsip atau teknik guna melakukan suatu rancangan pada sistem dan tata kerja yang penggunaannya paling efektif dan efisien.

\section{Systematic Layout Planning (SLP)}

Pembuatan perancangan layout menggunakan Systematic Layout Planing (SLP) berfungsi untuk menyelesaikan sebuah permasalahan yang menyangkut berbagai macam problem baik pada produksi, transportasi, pergudangan, ataupun aktivitas - aktivitas perkantoran lainnya. [7]

Berdasarkan pada 5 elemen dasar tata letak diharapkan susunan lantai produksi dapat sesuai dengan kebutuhan perusahaan. Adapun 5 elemen tersebut yaitu produk, kuantitas, proses, sistem pendukung, dan waktu. [8]

1) From To Chart (FTC)

From To Chart (FTC) adalah suatu teknik yang diterapkan untuk melakukan perencanaan layout dari fasilitas atau lantai produksi. Sebelum melakukan analisis, harus diketahui terlebih dahulu stasiun kerja apa saja yang ada atau terlibat dalam produksi.

Kegunaan dari from-to chart, antara lain digunakan untuk menganalisis perpindahan bahan guna mengetahui keterkaitan antar lintas produksi dan menunjukkan adanya ketergantungan pada satu kegiatan dengan kegiatan lainnya, juga keterkaitan antara beberapa bahan, komponen - komponen produk itu sendiri, dan sebagainya yang terlibat dalam produksi.

\section{2) Activity Relation Chart (ARC)}

Activity Relationship Chart adalah digram yang digunakan untuk mengetahui hubungan dari antar aktivitas suatu produksi pada tata letak fasilitas berdasarkan derajat hubungan aktivitas atas pertimbangan - pertimbangan yang bersifat subyektif untuk kemudian dinyatakan dalam penilaian kualitatif, sehingga mudah untuk menentukan kegiatan yang penempatan stasiun kerjanya harus berdampingan dan yang harus berjauhan.

Activity Relationship Chart (ARC) berfungsi untuk menampilkan keterkaitan antar stasiun kerja pada suatu produksi dalam mengerjakan produk. Dengan adanya ARC dapat ditentukan tingkat kedekatan antar proses satu dengan proses lainnya. [9]
Kegiatan atau operasi kerja ditentukan dengan dibuat suatu pengelompokan letaknya berdasarkan derajat keterdekatan dan dituliskan menggunakan kode huruf untuk menjelaskan derajat hubungan dari kegiatan produksi secara kualitatif sedangkan kode angka merupakan dasar dari penggunaan kode huruf tersebut.

Kode huruf yang digunakan memiliki arti sebagai berikut:

$\mathrm{A}=$ Mutlak penempatan stasiun kerja tersebut harus didekatkan

$\mathrm{E}=$ Sangat penting untuk penempatan stasiun kerja tersebut berdekatan.

$\mathrm{I}=$ Penting penempatan stasiun kerja tersebut untuk berdekatan.

$\mathrm{O}=$ Tidak diharuskan berdekatan dan bisa dilakukan dimana saja

$\mathrm{U}=$ Tidak perlu berdekatan atau keterkaitan geografis apapun.

$\mathrm{X}=$ Dijauhkan penempatan aktivitas tersebut tidak diperbolehkan untuk berdekatan

Kode huruf yang menjelaskan derajat hubungan antara setiap stasiun kerja ini secara khusus telah distandarkan sesuai pada Tabel 1 .

TABEL I

\begin{tabular}{|c|c|}
\hline $\begin{array}{l}\text { Kode } \\
\text { Alasan }\end{array}$ & Deskripsi Alasan \\
\hline 1 & Penggunaan catatan secara bersama \\
\hline 2 & Menggunakan tenaga kerja yang sama \\
\hline 3 & Menggunakan space area yang sama \\
\hline 4 & $\begin{array}{l}\text { Derajat kontak personel yang sering } \\
\text { dilakukan }\end{array}$ \\
\hline 5 & $\begin{array}{l}\text { Derajat kontak kertas kerja yang sering } \\
\text { dilakukan }\end{array}$ \\
\hline 6 & Urutan aliran kerja \\
\hline 7 & Melaksanakan kegiatan kerja yang sama \\
\hline 8 & Menggunakan peralatan kerja yang sama \\
\hline 9 & $\begin{array}{l}\text { Kemungkinan adanya bau yang tidak } \\
\text { mengenakan, ramai, dll. }\end{array}$ \\
\hline
\end{tabular}

KODE ANGKA PADA ACTIVITY RELATIONSHIP CHART (ARC)

\section{Ongkos Material Handling (OMH)}

Material handling yaitu salah satu jenis pengangkutan yang diterapkan pada suatu produksi, yaitu proses perpindahan bahan baku, barang kondisi setengah jadi ataupun barang jadi yang dikerjakan satu stasiun kerja ke titik lainnya.

Hubungan antara penanganan material seperti perpindahan material dan pengerjaan material (produk) dengan tata letak stasiun kerja pada sistem manufaktur merupakan dua kegiatan yang memiliki pengaruh satu sama lain. Hubungan antara dua kegiatan tersebut berkaitan dengan data yang dibutuhkan untuk membuat rancangan dari tiap kegiatan, tujuan umum, pengaruh penempatan stasiun kerja dan pola aliran. Perancangan ulang tata letak pabrik dapat dilaksanakan dengan menggunakan informasi mengenai besar ruangan yang dibutuhkan untuk setiap stasiun kerja sehingga dapat diketahui total biaya perpindahan material 
yang minimum. Oleh karena itu dalam membuat suatu perancangan tata letak perlu diketahui panjang jalur lintasan perpindahan material, waktu perpindahan, sumber dan tujuan perpindahan.

\section{1) Alat Angkut}

Untuk menentukan alat angkut yang akan digunakan perlu diperhatikan berat bahan material yang diangkut harus disesuaikan dengan maksimal daya angkut, bentuk dan jenis material.

Adapun terdapat alat angkut yang biasa digunakan dalam proses produksi diantaranya: alat angkut dengan menggunakan Tenaga Manusia ( 0 $30 \mathrm{Kg}$ ) membutuhkan biaya Rp. 150, alat angkut dengan menggunakan Handlift $(30-100 \mathrm{Kg})$ membutuhkan biaya Rp. 200, alat angkut dengan menggunakan Forklift (diatas $100 \quad \mathrm{Kg}$ ) membutuhkan biaya Rp. 250.

\section{2) Jarak Pengangkutan}

Ukuran yang dipergunakan banyak tergantung dari adanya personil yang memenuhi syarat, waktu untuk mengumpulkan data, dan jenis sistem pemindahan material yang digunakan. [10]

Jarak Euclidean, yaitu jarak yang didapat dengan mengukur lurus antara pusat stasiun kerja satu dengan pusat stasiun kerja lainnya.

$$
\operatorname{dij}=[(x i-x j) 2+(y i-y j) 2]^{1 / 2}
$$

Dimana: $\mathrm{d}=$ jarak antara $\mathrm{x}$ dan $\mathrm{y}$

$$
\mathrm{xi}=\text { data pada pusat stasiun kerja ke-i }
$$

yi = data pada setiap data ke-i

Jarak Rectilinear disebut juga dengan Jarak Manhattan, yaitu jarak yang dihitung seacara tegak lurus dari jalur disebut dengan Jarak Manhattan. Pengukuran dengan jarak rectilinear merupakan salah satu pengukuran yang sering digunakan karena mudah perhitungannya, mudah dimengerti dan sesuai dengan beberapa masalah di kehidupan nyata, misalkan untuk menentukan jarak antar Gedung pada Universitas. Pengkuran jarak rectilinear dapat dituliskan kedalam persamaan sebagai berikut:

$$
\operatorname{dij}=|x i-x j|+|y i+y j|
$$

Dimana, $\mathrm{x}$ dan $\mathrm{y}$ adalah posisi pelanggan

$\mathrm{d}=$ jarak antara $\mathrm{x}$ dan $\mathrm{y}$

$\mathrm{xi}=$ koordinat pada pusat stasiun $\mathrm{ke}-\mathrm{i}$

yi $=$ koordinat pada setiap data ke-i

Square Euclidean, yaitu ukuran jarak dengan mengkuadratkan bobot terbesar dari jarak antara dua fasilitas yang berdekatan. Pada beberapa persoalan lokasi dari suatu fasilitas dapat diselesaikan dengan penerapan square Euclidean yang dituliskan padaa persamaan dibawah ini

$$
\operatorname{dij}=[(x i-x j) 2+(y i \text { yj) 2] }
$$

\section{HASIL PENELITIAN}

\section{A. Alur Poduksi Vulkanisir}

Proses produksi ban vulkanisir diantaranya sebagai berikut;

1) Pemeriksaan Awal (Inspection), yaitu pemilahan bahan untuk memisahkan bahan yang masih bias diperbaiki dengan bahan yang sudah tidak dapat diperbaiki.

2) Buffing adalah proses pemarutan permukaan ban atau tread ban menggunakan mesin yang dioperasikan oleh manusia dalam pengerjaannya. Proses ini dilakukan kurang lebih selama 5 menit untuk menyelesaikan satu ban menggunakan mesin buffing

3) Kniving, yaitu pemarutan kembali menggunakan mesin gerinda tangan tangan. Waktu pengerjaan setiap ban berbeda tergantung dengan kondisi ban setelah pemarutan (buffing).

4) Pengeleman permukaan bahan dibagi menjadi dua tahapan yaitu, tahap pertama adalah pengeleman dengan lem cair dan tahap kedua adalah pengeleman dengan cushion gum.

5) Repair \& Building. Repair yaitu proses perbaikan permukaan (casing) ban seperti lubang, cekungan dan retakan yang terdapat pada casing ban akan ditutup dengan dengan menggunakan cushion gum. Building adalah membuat lapisan cushion gum pada permukaan ban yang nantinya akan ditempelkan tread liner dibantu dengan mesin press. Sebelum ban dipasang pada mesin, sebelumnya ban telah dipasang ban perut dan ban dalam.

6) Pemasangan Ban Dalam dan Ban Perut. Pada proses ini casing ban yang sudah terpasang tread liner akan dimasukkan ban dalam dan ban perut

7) Chamber, yaitu proses pemasakan atau pemanasan ban dimana proses ini bertujuan agar cushion gum untuk merekatkan tread liner dapat menyatu dengan baik. Proses ini menggunakan mesin Chamber sengan waktu penasan atau pemasakan selama 3 jam 40 menit. Sebelum ban dimasukkan kedalam mesin chamber, ban dipasangkan rim dan envelope.

8) Melepas Rim (Velg), Envelope, Ban Dalam, dan Ban Perut yaitu melepaskan seluruh pelengkap yang digunakan pada ban saat proses curing

\section{9) Penyemiran}

Proses penyemiran dilakukan saat ban masih dalam keadaan panas agar cat dapat menempel dengan baik pada ban.

10) Pemberian No. Seri

Pemberian nomor seri pada ban dilakukan dengan cara memanaskan besi yang sudah memiliki 
cetakan angka untuk kemudian ditempelkan pada permukaan ban.

\section{B. Layout Keseluruhan}

Lahan yang terbatas dan tenaga kerja sebanyak 3 orang menyebabkan banyak kegiatan yang tidak memiliki stasiun kerja khusus atau terjadi di dua stasiun seperti untuk kegiatan pengeleman yang berada di tempat yang sama, dan kegiatan building dilakukan di stasiun yang memiliki lebih dari satu kegiatan yaitu kegiatan kniving, pemasangan ban dalam dan ban perut, dan press.

\section{1) Layout Keseluruhan (Sekarang)}

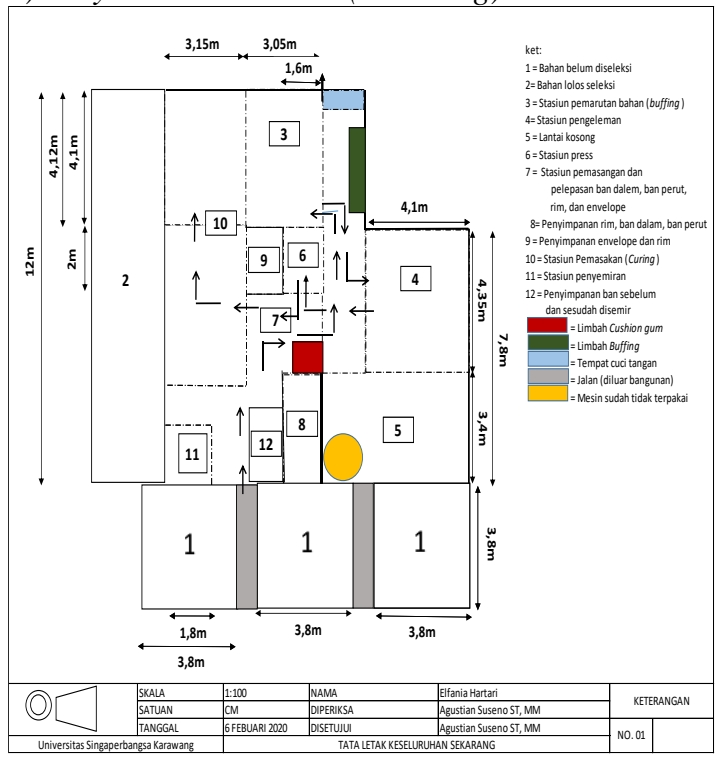

Gambar 2. Layout Lintasan Keseluruhan (Sekarang) Bagian Vulkanisir

Berdasarkan layout tersebut dapat diketahui bahwa jalur lintasan untuk dilalui perpindahan baik barang maupun pekerja belum efisien karena hanya terdapat satu jalur untuk arus bolak balik.

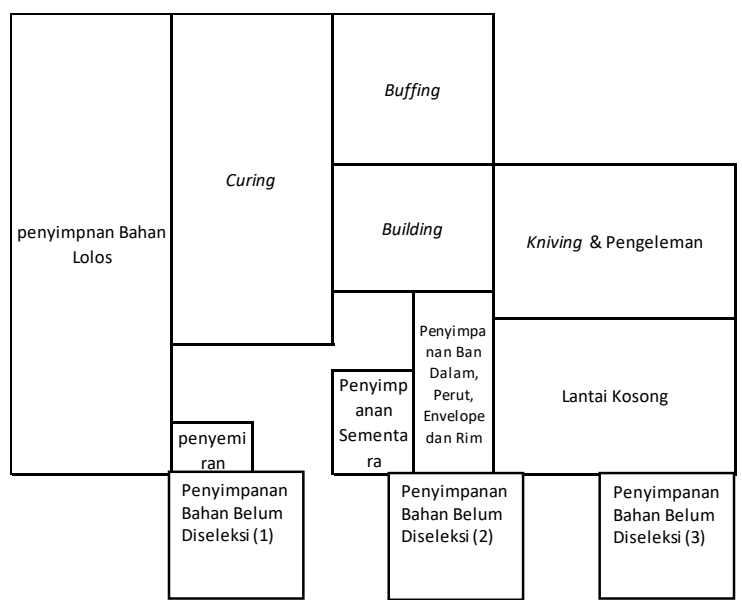

Gambar 3. Layout Stasiun Kerja (Sekarang)
TABEL II

DATA LUAS LANTAI SEKARANG

\begin{tabular}{|c|c|c|c|c|c|}
\hline No. & Nama Bagian & $\begin{array}{c}\text { K } \\
\text { od } \\
\text { e }\end{array}$ & $\begin{array}{c}\text { Panjan } \\
\text { g (m) }\end{array}$ & $\begin{array}{l}\text { Leba } \\
\mathbf{r}(\mathrm{m})\end{array}$ & $\begin{array}{c}\text { Luas } \\
\left(\mathbf{m}^{2}\right)\end{array}$ \\
\hline 1. & Receiving 1 & $\mathrm{~A}$ & 2,8 & 12 & 33,6 \\
\hline 2. & Receiving 2 (3) & B & 1,8 & 1,8 & 9,72 \\
\hline 3. & Buffing & $\mathrm{C}$ & 3,05 & 4,1 & 12,505 \\
\hline 4. & Kniving & $\mathrm{D}$ & 4,1 & 4,35 & 18,27 \\
\hline 5. & Pengeleman & $\mathrm{E}$ & 4,1 & 4,35 & 18,27 \\
\hline 6. & Cushion Gum & $\mathrm{F}$ & 4,1 & 4,35 & 18,27 \\
\hline 7. & $\begin{array}{l}\text { Assy } 1 \text { (Ban } \\
\text { dalam \& Ban } \\
\text { Perut) }\end{array}$ & G & 3,05 & 2,5 & 7,625 \\
\hline 8. & $\begin{array}{l}\text { Press ( } \\
\text { Pemasangan } \\
\text { Tread Liner) }\end{array}$ & $\mathrm{H}$ & 1,6 & 2 & 3,2 \\
\hline 9. & $\begin{array}{l}\text { Assy } 2 \\
\text { (Envelope \& } \\
\text { Rim) }\end{array}$ & I & 3,05 & 2,5 & 7,625 \\
\hline 10. & Curing & $\mathbf{J}$ & 3,15 & 9,03 & 28,44 \\
\hline 11. & $\begin{array}{l}\text { Bongkar Rim, } \\
\text { Envelope, Ban } \\
\text { Dalam \& Ban } \\
\text { Perut }\end{array}$ & K & 1,6 & 2 & 3,2 \\
\hline 12. & $\begin{array}{l}\text { Penyimpanan } \\
\text { sebelum semir }\end{array}$ & $\mathrm{L}$ & 1,35 & 2,26 & 3,051 \\
\hline 13. & Penyemiran & M & 1,9 & 1,8 & 4,42 \\
\hline 14. & $\begin{array}{l}\text { Penyimpanan } \\
\text { sesudah semir }\end{array}$ & $\mathrm{N}$ & 1,35 & 2,26 & 3,051 \\
\hline
\end{tabular}

2) Layout Keseluruhan (Usulan)

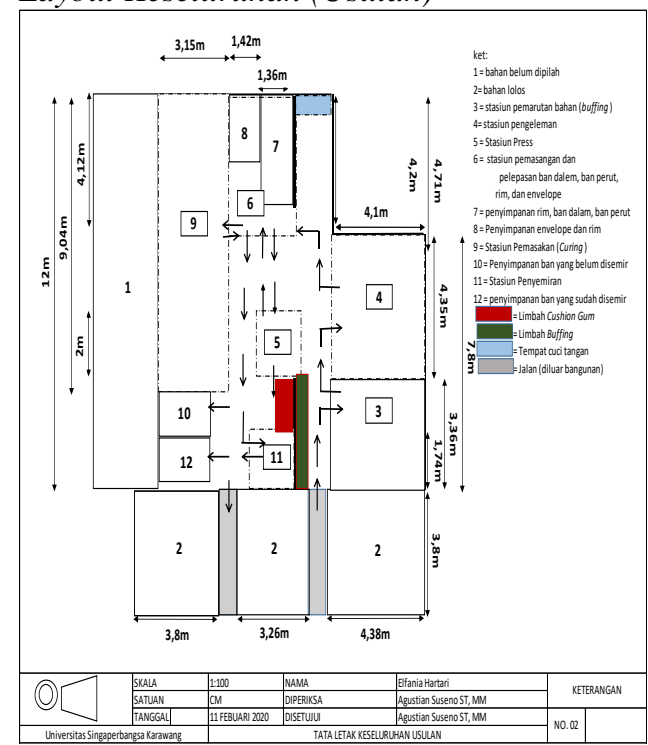

Gambar 4. Layout Lintasan Keseluruhan (Usulan) Bagian Vulkanisir

Berdasarkan hasil dari perancangan ulang didapat layout usulan di atas, lahan yang tersedia telah dimanfaatkan dengan maksimal dan jalur lintasan perpindahan lebih teratur. 
Jurnal Media

Teknik dan

Sistem Industri

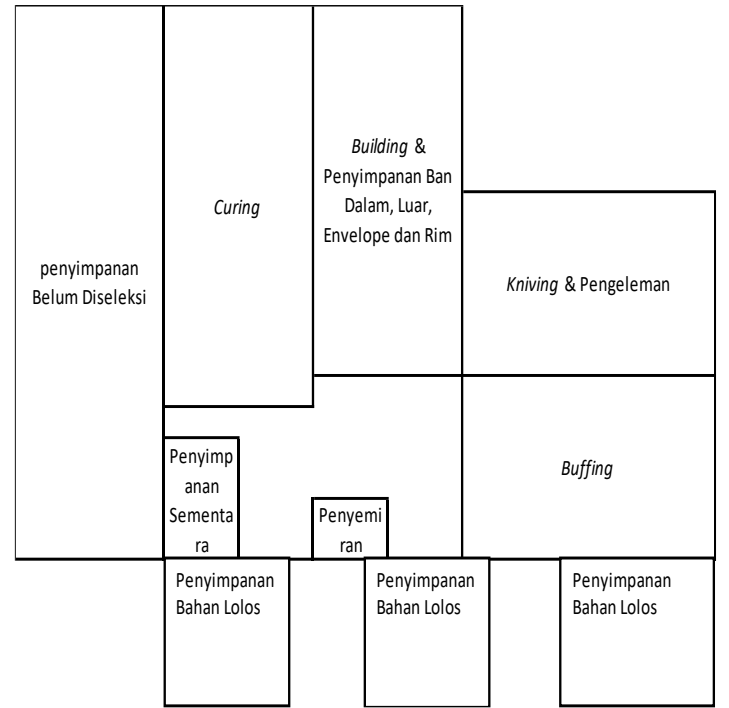

Gambar 5. Layout Stasiun Kerja (Usulan)

TABEL III

DATA LUAS LANTAI USULAN

\begin{tabular}{clcccc}
\hline No. & \multicolumn{1}{c}{$\begin{array}{c}\text { Nama } \\
\text { Bagian }\end{array}$} & Kode & $\begin{array}{c}\text { Panjan } \\
\mathbf{g}(\mathbf{m})\end{array}$ & $\begin{array}{c}\text { Lebar } \\
(\mathbf{m})\end{array}$ & $\begin{array}{c}\text { Luas } \\
\left(\mathbf{m}^{2}\right)\end{array}$ \\
\hline 1. & Receiving 1 & $\mathrm{A}$ & 1,8 & 1,8 & 9,72 \\
2. & Receiving 2 & $\mathrm{B}$ & 2,8 & 12 & 33,6 \\
3. & Buffing & $\mathrm{C}$ & 4,2 & 3,36 & 14,112 \\
4. & Kniving & $\mathrm{D}$ & 4,35 & 4,16 & 18,096 \\
5. & Pengeleman & $\mathrm{E}$ & 4,35 & 4,16 & 18,096 \\
6. & Cushion Gum & $\mathrm{F}$ & 4,35 & 4,16 & 18,096 \\
7. & Assy 1 (Ban & $\mathrm{G}$ & 3,05 & 4,2 & 12,81 \\
& dalam \& Ban & & & & \\
& Perut) & & & & \\
8. & Press & $\mathrm{H}$ & 2 & 2 & 3,2 \\
& (Pemasangan & & & & \\
& Tread Liner) & & & & \\
9. & Assy 2 & $\mathrm{I}$ & 3,05 & 4,2 & 12,81 \\
& (Envelope \& & & & & \\
& Rim) & & & & \\
10. & Curing & $\mathrm{J}$ & 3,15 & 9,03 & 28,44 \\
11. & Bongkar Rim, & $\mathrm{K}$ & 1,6 & 2 & 3,2 \\
& Envelope, & & & & \\
& & & & & \\
\hline
\end{tabular}

\begin{tabular}{|c|c|c|c|c|c|}
\hline No. & $\begin{array}{l}\text { Nama } \\
\text { Bagian }\end{array}$ & Kode & $\begin{array}{c}\text { Panjan } \\
\text { g (m) }\end{array}$ & $\begin{array}{c}\text { Lebar } \\
\text { (m) }\end{array}$ & $\begin{array}{c}\text { Luas } \\
\left(\mathbf{m}^{2}\right)\end{array}$ \\
\hline & $\begin{array}{l}\text { Ban Dalam \& } \\
\text { Ban Perut }\end{array}$ & & & & \\
\hline 12. & $\begin{array}{l}\text { Penyimpanan } \\
\text { Sebelum } \\
\text { Semir }\end{array}$ & $\mathrm{L}$ & 1,25 & 2,26 & 2,285 \\
\hline 13. & Penyemiran & $\mathrm{M}$ & 2 & 1,8 & 3,6 \\
\hline 14. & $\begin{array}{l}\text { Penyimpanan } \\
\text { sesudah semir }\end{array}$ & $\mathrm{N}$ & 1,25 & 2,26 & 2,285 \\
\hline
\end{tabular}

Berdasarkan dari layout sekarang dan usulan yng telah dibuat dapat diketahui perbandingan dari jarak lintasan kedua layout tersebut. Berikut merupakan perbandingan jarak lintasan layout sekarang dan usulan.

TABEL IV

PERBANDINGAN JARAK LINTASAN LAYOUT SEKARANG USULAN

\begin{tabular}{ccccc}
\hline No. & Dari & Ke & $\begin{array}{c}\text { Jarak Layout } \\
\text { Sekarang } \\
(\mathbf{m})\end{array}$ & $\begin{array}{c}\text { Jarak Layout } \\
\text { Usulan (m) }\end{array}$ \\
\hline 1. & A & B & 1,95 & 1,95 \\
2. & B & C & 27,4 & 4,3 \\
3. & C & D & 2,12 & 3,38 \\
4. & D & E & 0 & 0 \\
5. & E & F & 0 & 0 \\
6. & F & G & 2,7 & 2,3 \\
7. & G & H & 0,85 & 2,32 \\
8. & H & I & 0,85 & 2,32 \\
9. & I & J & 1,2 & 0,8 \\
10. & J & K & 1,2 & 0,8 \\
11. & K & L & 1,55 & 1 \\
& tal & & 39,82 & 19,17 \\
\hline
\end{tabular}

\section{Flow To Chart (FTC)}

Berikut merupakan Flow To Chart yang berisikan data jarak lintasan antar stasiun kerja dalam produksi ban vulkanisir.

\begin{tabular}{|c|c|c|c|c|c|c|c|c|c|c|c|c|c|c|c|}
\hline From/To & $\mathbf{A}$ & B & C & D & $\mathbf{E}$ & $\mathbf{F}$ & $\mathbf{G}$ & $\mathbf{H}$ & I & $\mathbf{J}$ & $\mathbf{K}$ & $\mathbf{L}$ & $\mathbf{M}$ & $\mathbf{N}$ & Total \\
\hline $\mathbf{A}$ & & 1,95 & & & & & & & & & & & & & 1,95 \\
\hline B & & & 27,40 & & & & & & & & & & & & 27,40 \\
\hline $\mathrm{C}$ & & & & 2,12 & & & & & & & & & & & 2,12 \\
\hline D & & & & & 0,00 & & & & & & & & & & 0,00 \\
\hline $\mathbf{E}$ & & & & & & 0 & & & & & & & & & 0 \\
\hline $\mathbf{F}$ & & & & & & & 2,70 & & & & & & & & 2,70 \\
\hline $\mathbf{G}$ & & & & & & & & 0,85 & & & & & & & 0,85 \\
\hline $\mathbf{H}$ & & & & & & & & & 0,85 & & & & & & 0,85 \\
\hline I & & & & & & & & & & 1,20 & & & & & 1,20 \\
\hline $\mathbf{J}$ & - & & & & & & & & & & 1,20 & & & & 1,20 \\
\hline $\mathbf{K}$ & & & & & & & & & & & & 2,2 & & & 2,2 \\
\hline $\mathbf{L}$ & & & & & & & & & & & & & 1,55 & & 1,55 \\
\hline $\mathbf{M}$ & & & & & & & & & & & & & & 1,55 & 1,55 \\
\hline $\mathbf{N}$ & & & & & & & & & & & & & & & - \\
\hline
\end{tabular}

Gambar 6. Flow To Chart (FTC) Sekarang 


\begin{tabular}{|c|c|c|c|c|c|c|c|c|c|c|c|c|c|c|c|}
\hline From/To & A & B & C & D & $\mathbf{E}$ & $\mathbf{F}$ & G & H & I & $\mathbf{J}$ & $\mathbf{K}$ & $\mathbf{L}$ & M & $\mathbf{N}$ & Total \\
\hline $\mathbf{A}$ & & 1,95 & & & & & & & & & & & & & 1,95 \\
\hline B & & & 4,30 & & & & & & & & & & & & 4,30 \\
\hline C & & & & 3,38 & & & & & & & & & & & 3,38 \\
\hline D & & & & & 0 & & & & & & & & & & 0,00 \\
\hline $\mathbf{E}$ & & & & & & 0 & & & & & & & & & 0 \\
\hline $\mathbf{F}$ & & & & & & & 2,30 & & & & & & & & 2,30 \\
\hline G & & & & & & & & 2,32 & & & & & & & 2,32 \\
\hline H & & & & & & & & & 2,32 & & & & & & 2,32 \\
\hline I & & & & & & & & & & 0,80 & & & & & 0,80 \\
\hline $\mathbf{J}$ & - & & & & & & & & & & 0,80 & & & & 0,80 \\
\hline $\mathbf{K}$ & & & & & & & & & & & & 5,4 & & & 5,4 \\
\hline L & & & & & & & & & & & & & 1 & & 1 \\
\hline M & & & & & & & & & & & & & & 1 & 1 \\
\hline $\mathbf{N}$ & & & & & & & & & & & & & & & - \\
\hline
\end{tabular}

Gambar 7. Flow To Chart (FTC) Usulan

\section{Activity Relation Chart (ARC)}

ARC ini dibuat atas dasar keterkaitan kegiatan antar stasiun kerja yang terdapat di Unit Manufaktur bagian Vulkanisir Ban PT. Adhimix
Precast Indonesia akan dituliskan secara lebih jelas dan lengkap untuk setiap stasiunnya dapat dilihat dalam Gambar dibawah ini.

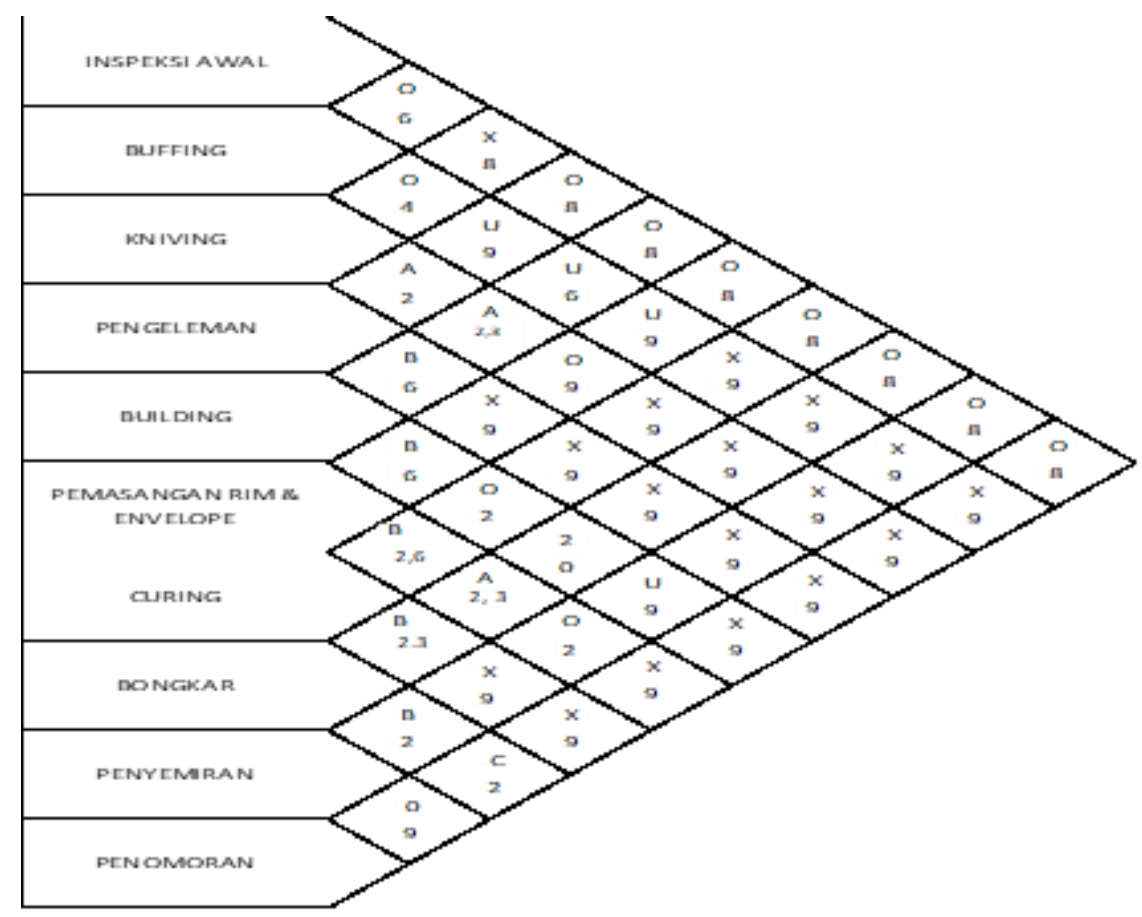

Gambar 8. Activity Relationship Chart (ARC)

Pada Gambar 8 dapat diketahui hubungan keterkaitan dari satu stasiun kerja ke stasiun yang lain dalam proses produksi ban vulkanisir secara rinci.

\section{E. Ongkos Material Handling $(\mathrm{OMH})$}

Ongkos material handling (sekarang) atau $\mathrm{OMH}$ sekarang adalah hasil perhitungan berdasarkan layout yang saat ini digunakan oleh perusahaan. Berdasarkan dari data aktual yang didapat maka dapat dihitung besar Ongkos Material Handling OMH untuk proses vulkanisir dapat dilihat pada Tabel V.
TABEL $\mathrm{V}$

ONGKOS MATERIAL HANDLING (SEKARANG)

\begin{tabular}{cccccc}
\hline Dari & Ke & Frekwensi & $\begin{array}{c}\text { Jara } \\
\mathbf{k} \\
(\mathbf{m})\end{array}$ & $\begin{array}{c}\text { OMH/m } \\
\text { Gerakan } \\
(\mathbf{R p})\end{array}$ & $\begin{array}{c}\text { Total } \\
\text { OMH } \\
(\mathbf{R p} .)\end{array}$ \\
\hline A & B & 400 & 1,95 & 150 & 117.000 \\
B & C & 400 & 4,3 & 150 & 258.000 \\
C & D & 400 & 3,38 & 150 & 202.800 \\
D & E & 400 & 0 & 150 & 0 \\
E & F & 400 & 0 & 150 & 0 \\
F & G & 400 & 2,3 & 150 & 138.000 \\
G & H & 400 & 2,32 & 150 & 139.200 \\
\hline
\end{tabular}


Jurnal Media

Teknik dan

Sistem Industri

\begin{tabular}{cccccc}
\hline Dari & Ke & Frekwensi & $\begin{array}{c}\text { Jara } \\
\mathbf{k} \\
(\mathbf{m})\end{array}$ & $\begin{array}{c}\text { OMH/m } \\
\text { Gerakan } \\
(\mathbf{R p})\end{array}$ & $\begin{array}{c}\text { Total } \\
\text { OMH } \\
(\mathbf{R p} .)\end{array}$ \\
\hline H & I & 400 & 2,32 & 150 & 139.200 \\
I & J & 400 & 0,8 & 150 & 48.000 \\
J & K & 400 & 0,8 & 150 & 48.000 \\
K & L & 400 & 5,4 & 150 & 324.000 \\
L & M & 400 & 1 & 150 & 60.000 \\
M & N & 400 & 1 & 150 & 60.000 \\
\hline \multicolumn{2}{r}{ Total } & $\mathbf{5 2 0 0}$ & $\mathbf{2 5 , 5}$ & $\mathbf{1 9 5 0}$ & $\begin{array}{c}\mathbf{1 . 5 3 4 . 2 0} \\
\mathbf{7}\end{array}$ \\
\hline
\end{tabular}

Maka untuk Ongkos Material Handling (OMH) yang dibutuhkan untuk layout sekarang adalah Rp. 2.614.200. Ongkos material handling (usulan) atau $\mathrm{OMH}$ usulan merupakan hasil perhitungan yang didapat berdasarkan layout usulan.

TABEL VI

ONGKOS MATERIAL HANDLING (USULAN)

\begin{tabular}{|c|c|c|c|c|c|}
\hline$\underset{\mathbf{i}}{\text { Dar }}$ & $\begin{array}{l}\mathbf{K} \\
\mathbf{e}\end{array}$ & $\begin{array}{c}\text { Frekwens } \\
\text { i }\end{array}$ & $\begin{array}{c}\text { Jara } \\
\text { k (m) }\end{array}$ & $\begin{array}{c}\text { OMH/m } \\
\text { Geraka } \\
\text { n (Rp) } \\
\end{array}$ & $\begin{array}{c}\text { Total } \\
\text { OMH } \\
\text { (Rp.) } \\
\end{array}$ \\
\hline A & B & 400 & 1,95 & 150 & $\begin{array}{l}117.000 \\
1.644 .00\end{array}$ \\
\hline B & $\mathrm{C}$ & 400 & 27,4 & 150 & 0 \\
\hline $\mathrm{C}$ & $\mathrm{D}$ & 400 & 2,12 & 150 & 127.200 \\
\hline $\mathrm{D}$ & $\mathrm{E}$ & 400 & 0 & 150 & 0 \\
\hline $\mathrm{E}$ & $\mathrm{F}$ & 400 & 0 & 150 & 0 \\
\hline $\mathrm{F}$ & G & 400 & 0,85 & 150 & 51.000 \\
\hline $\mathrm{G}$ & $\mathrm{H}$ & 400 & 0,85 & 150 & 51.000 \\
\hline $\mathrm{H}$ & I & 400 & 2,7 & 150 & 162.000 \\
\hline I & $\mathrm{J}$ & 400 & 1,2 & 150 & 72.000 \\
\hline $\mathrm{J}$ & K & 400 & 1,2 & 150 & 72.000 \\
\hline $\mathrm{K}$ & $\mathrm{L}$ & 400 & 2,2 & 150 & 132.000 \\
\hline $\mathrm{L}$ & M & 400 & 1,55 & 150 & 93.000 \\
\hline $\mathrm{M}$ & $\mathrm{N}$ & 400 & 1,55 & 150 & 93.000 \\
\hline \multicolumn{2}{|c|}{ Total } & 5200 & 43,57 & 1950 & $\begin{array}{c}2.614 .20 \\
0 \\
\end{array}$ \\
\hline
\end{tabular}

Maka untuk Ongkos Material Handling (OMH) yang dibutuhkan untuk layout usulan adalah Rp. 1.534.200. KESIMPULAN

Berdasarkan dari hasil perhitungan total biaya yang dibutuhkan untuk OMH pada layout sekarang yang telah dijabarkan pada Tabel $\mathrm{V}$ didapat hasil sebesar Rp 2.614.200 dengan total jarak lintasan $39,82 \mathrm{~m}$ dan ongkos material handling usulan pada Tabel IV didapat hasil sebesar Rp. 1.534.200 dengan total jarak lintasan 19,17m, hal ini membuktikan bahwa layout usulan berdasarkan optimalisasi jarak menggunakan metode SLP dapat diterapkan karena terjadi penurunan total ongkos material handling dengan besar $35,44 \%$ atau $\mathrm{Rp}$. 926.580. Oleh karena itu, layout usulan dianggap penggunaannya akan lebih maksimal dan berhasil meminimalkan biaya perpindahan barang dibandingkan dengan menggunakan layout sekarang.

Layout usulan dibuat dengan membuat rancangan ulang dari posisi stasiun kerja sesuai dengan jalur lintasan perpindahan material maupun pekerja. Adanya rancangan ulang ini membuktikan bahwa dengan hanya mengatur letak stasiun kerja dapat mengurangi terjadinya arus bolak - balik ataupun persilangan alur produksi serta dapat memanfaatkan lahan kosong yang sebelumnya tidak dipergunakan dengan baik dapat digunakan dengan maksimal.

\section{REFERENSI}

[1] F. R. Merry Siska, "Rancang Ulang Tata Letak CV. Sumber Vulkanisir Super Menggunakan Metode Konvensional dan CRAFT," Jurnal Sains, Teknologi dan Industri, Vol. 14, No. 2, Juni 2017, pp.225 - 233, p. 9, 2014.

[2] Y. Hermawan, "Pengembangan Dan Analisis Ergonomi Kursi Operator Mesin Vulkanisir Ban Dengan Metode Reverse Engineering," ROTOR, p. 10, 2011.

[3] F. S. Merry Siska, "Perancangan Ulang Tata Letak Pabrik Vulkanisir Ban," Seminar Nasional Teknologi Informasi, Komunikasi dan Industri (SNTIKI) 8, p. 12, 2016.

[4] Pamularsih, "Usulan Rancangan Tata Letak Fasilitas Menggunakan Metode Automated Layout Design Program (ALDEP) di Edem Ceramic," Jurnal Online Institut Teknologi Nasional, ISSN: 2338-5081, Vol. 03, No. 02. Jurusan Teknik Industri,, 2015.

[5] A. S. A. B. Rionaldi Yuliant, "Usulan Perancangan Tata Letak Fasilitas Perusahaan Garmen Cv. X Dengan Menggunakan Metode Konvensional," Jurnal Online Institut Teknologi Nasional, p. 12, 2014.

[6] M. C. W. A. Agnes Novita Ningtyas, "Perancangan Ulang Tata Letak Fasilitas Produksi Dengan Metode Grafik Dan Craft Untuk Minimasi Ongkos Material Handling," Jurnal Rekayasa dan Manajemen Sistem Industri Vol. 3 No. 3 Teknik Industri Universitas Brawijaya, p. 10, 2015.

[7] A. I. Dede Muslim, "Usulan Perbaikan Tata Letak Fasilitas Terhadap Optimalisasi Jarak dan Ongkos Material Handling dengan Pendekatan Systematic Layout Planning (SLP) di PT Transplant Indonesia," Jurnal Media Teknik \& Sistem Industri, p. 8, 2018.

[8] L. W. Y. P. Nofi Erni, "Usulan Perancangan Ulang Tata Letak Pabrik Pada PT. XYZ,' Jurnal Ilmiah Teknik Inustri, p. 13, 2013.

[9] B. S. d. R. N. Anwar, "Usulan Perbaikan Tata Letak Pabrik dengan Menggunakan SystematicLayout Planning (SLP) di CV. Arasco Bireuen," Malikussaleh Industrial Engineering Journal Vol.4 No.2 (2015) 4-10, p. 7, 2015.

[10] Z. A. A. P. Prapto Rahardjo, "Perancangan Ulang Tata Letak Stasiun Kerja Dengan Metode Systematic Lay Out Planning (Studi Kasus di PT. Infineon Technologies Batam)," PROFESIENSI, 2(2): 143-154, p. 12, 2014. 